\title{
Open necrosectomy combined with continuous positive drainage and prophylactic diverting loop ileostomy for late infected pancreatic necrosis: a retrospective cohort study
}

Dong-Guang Niu ${ }^{1,2}$, Wei-Qin Li ${ }^{1}$, Qian Huang ${ }^{1}$, Fan Yang ${ }^{1}$, Wei-Liang Tian ${ }^{1}$, Chen Li ${ }^{3}$, Lian-An Ding ${ }^{2}$, Hong-Chun Fang ${ }^{2}$ and Yun-Zhao Zhao ${ }^{1,4^{*}}$

\begin{abstract}
Background: To evaluate an innovative open necrosectomy strategy with continuous positive drainage and prophylactic diverting loop ileostomy for the management of late infected pancreatic necrosis (LIPN).

Methods: Consecutive patients were divided into open necrosectomy (ON) group ( $n=23)$, open necrosectomy with colonic segment resection (ON+CSR) group $(n=8)$ and open necrosectomy with prophylactic diverting loop ileostomy (ON+PDLI) group $(n=11)$. Continuous positive drainage (CPD) via double-lumen irrigation-suction tube (DLIST) was performed in ON+PDLI group. The primary endpoints were duration of organ failure after surgery, postoperative complication, the rate of re-surgery and mortality. The secondary endpoints were duration of hospitalization, cost, time interval between open surgery and total enteral nutrition (TEN).
\end{abstract}

Results: The recovery time of organ function in ON+PDLI group was shorter than that in other two groups. Colonic complications occurred in 13 patients (56.5\%) in the ON group and 3 patients (27.3\%) in the ON+PDLI group $(p=$ $0.11)$. The length of stay in the ON+PDLI group was shorter than the ON group $(p=0.001)$. The hospitalization cost in the ON+PDLI group was less than the ON group ( $p=0.0052)$.

Conclusion: ON+PDLI can avoid the intestinal dysfunction, re-ileostomy, the resection of innocent colon and reduce the intraoperative trauma. Despite being of colonic complications before or during operation, CPD + PDLI may show superior effectiveness, safety, and convenience in LIPN.

Keywords: Infected pancreatic necrosis, Open necrosectomy, Prophylactic diverting loop ileostomy, Continuous positive drainage

\footnotetext{
*Correspondence: yz_zhao@aliyun.com

'Department of General Surgery, Jinling clinical college of Nanjing Medical University, Nanjing 210002, Jiangsu, China

${ }^{4}$ Department of General Surgery, Jinling clinical college of Nanjing Medical University, 305 East Zhongshan Road, Nanjing 210000, Jiangsu, China

Full list of author information is available at the end of the article
}

C C The Author(s). 2020 Open Access This article is licensed under a Creative Commons Attribution 4.0 International License, which permits use, sharing, adaptation, distribution and reproduction in any medium or format, as long as you give appropriate credit to the original author(s) and the source, provide a link to the Creative Commons licence, and indicate if changes were made. The images or other third party material in this article are included in the article's Creative Commons. licence, unless indicated otherwise in a credit line to the material. If material is not included in the article's Creative Commons licence and your intended use is not permitted by statutory regulation or exceeds the permitted use, you will need to obtain permission directly from the copyright holder. To view a copy of this licence, visit http://creativecommons.org/licenses/by/4.0/ The Creative Commons Public Domain Dedication waiver (http://creativecommons.org/publicdomain/zero/1.0/) applies to the data made available in this article, unless otherwise stated in a credit line to the data. 


\section{Background}

Severe acute pancreatitis (SAP) is a serious disease involving multiple disciplines and systems. A certain proportion of patients with SAP would develop infected pancreatic necrosis (IPN) in the later course of the disease [1]. IPN is a severe complication of SAP with mortality at about $30 \%(12-39 \%)$ [2-5]. As the treatment protocols sufficiently addressed the under lining pathophysiological mechanisms of the disease, the step-up approach with minimally invasive techniques is emerging as the main stream in the appropriate IPN patient $[6,7]$. However, less than $20 \%$ patients with LIPN who have failed in minimally invasive surgery still need to be treated with ON ultimately [8]. The operations used for LIPN are aimed at removing necrosis or devitalized tissue, draining pus, providing a safer avenue for egress of pancreatic secretions and the leakage of gastrointestinal tract and managing the colonic complications. Recurrent post necrosectomy local sepsis, due to inadequate drainage, continues to pose a major drawback $[9,10]$. In our central, continuous positive drainage (CPD) via doublelumen irrigation-suction tube (DLIST) is one of the key techniques by insert the DLIST into abscess, focus of necrotic and abdominal cavity during the procedure of $\mathrm{ON}$ for postoperative CPD, which could ensure the adequate drainage. For colon complications, resection with proximal ostomy and diverting loop ileostomy (DLI) constitutes the treatment for suspected imminent or overt ischemia/perforation in majority of cases $[11,12]$. However, just evaluating the outer aspect of the colon, identification of colon involvement may be difficult due to nonspecific symptoms or be masked by the sepsis. On one hand, $45.4 \%$ patients were detected with GI fistula after performing open necrosectomy. DLI, ileostomy or colostomy was performed for $65.3 \%$ colonic fistulas [13, 14]. On the other hand, with a low threshold for colonic resection due to unreliable detection of ischemia or imminent perforation by outside inspection during surgery for IPN, histologically examined specimens showed that colonic resection was unnecessary in $20-50 \%$ [12, $15,16]$. Postoperative mortality was as high as $50 \%$ [17]. However, up to now, comparing the role of DLI and the aggressive form of treatment such as subtotal/segment colectomy in terms of clinic outcome and prognosis, there is no data to suggest that which one is more advantageous in treating IPN patients with the suspected imminent or overt ischemia/perforation before or during operation. Also, there is no report about the merits of PDLI in ON for IPN without colonic complications before or during operation.

Therefore, in current study, we aimed to evaluate the effectiveness, safety, and convenience of CPD + PDLI in LIPN compared to the other two open necrosectomy approaches, no matter with or without colonic complications before or during operation.

\section{Methods \\ Patients}

From January 2012 to February 2017, all the consecutive patients admitted to our center with a diagnosis of IPN were registered in an internal database and screened for potential enrollment. Patients who were performed open pancreatic necrosectomy and diagnosed with IPN during the study period were collected. The data were assembled and analyzed retrospectively. Informed consent was exempted because this retrospective study was harmless to the patients and contained no personal data. The study was approved by the Institutional Review Board of Jinling hospital.

The inclusion criteria for the study were: (1) patients diagnosis with IPN according to the presence of gas bubbles within pancreatic necrosis on contrast-enhanced CT scan or a positive bacterial culture obtained by fineneedle aspiration, first drainage and/or operation [18]; (2) patients performed with open pancreatic necrosectomy and diagnosed with IPN.

The exclusion criteria were: (1) pregnant patients; (2) patients received chemotherapy for malignancy or autoimmune diseases; (3) patients received abdominal surgery before IPN and was present due to abdominal compartment syndrome (ACS), perforation of a visceral organ, bleeding during the current episode of AP; (4) patients received ON for IPN before admitting to our institute during the current episode of AP; (5) IPN was caused due to trauma (6) the treatment strategy was not completed for nonmedical reasons.

Initial medical treatment and minimally invasive stepup approach were carried out for every patient before and after IPN confirmation according to the international recommendations $[6,19]$.

\section{Endpoints}

For each participant, the following variables were collected, including age, sex, etiology, and body mass index (BMI), time interval between AP onset to operation. Baseline characteristics such as acute physiology and chronic health evaluation (APACHE) II score, sequential organ failure assessment (SOFA) score, laboratory data including C-reactive protein (CRP), procalcitonin (PCT), Interleukin-6 (IL-6) and white blood cells (WBC) were also collected and assessed within $24 \mathrm{~h}$ before surgery, at the third and seventh day after surgery.

Our primary endpoints were duration of organ failure after surgery, postoperative complication, the rate of resurgery and mortality. Secondary endpoints were duration of hospitalization, cost, time interval between open surgery to total enteral nutrition (TEN). The main 
postoperative complications included colonic complication, hemorrhage, pancreatic fistula. The colonic complications included colonic suspected imminent or overt ischemia/perforation, stenosis, hemorrhage, colonic fistula, pseudo-obstruction.

Organ functions were evaluated in cardiovascular, renal and respiratory systems. The criteria for cardiovascular, renal and respiratory failure were defined based on international consensus $[18,20]$, cardiovascular (systolic blood pressure $<90 \mathrm{mmHg}$ despite adequate fluid resuscitation or need for inotropic agent), renal [serum creatinine $\geq 171 \mu \mathrm{mol} / \mathrm{L}(2.0 \mathrm{mg} / \mathrm{dL})$ after rehydration and respiratory $[\mathrm{PaO} 2 / \mathrm{FiO} 2 \leq 300 \mathrm{mmHg}(40 \mathrm{kPa})]$.

Gastrointestinal fistula was defined as the discharge of the gastric contents, bowel from drain or surgical wound. Intra-abdominal bleeding was defined as peritoneal/retroperitoneal bleeding that required surgical, radiologic or endoscopic treatment. Gastrointestinal bleeding was defined as that the blood loss from the mouth to the rectum was more than $500 \mathrm{ml} / 24 \mathrm{~h}$.

\section{Minimally invasive step-up approach}

Percutaneous or endoscopic transgastric drainage was firstly performed. The preferred route was through the left retroperitoneum, thereby facilitating minimally invasive retroperitoneal necrosectomy at a later stage. If there was no clinical improvement after $72 \mathrm{~h}$ and if the position of the drain was inadequate or other fluid collections could be drained, a second drainage procedure would be performed. If this was not possible, or if there was no clinical improvement after an additional $72 \mathrm{~h}$, then, video-assisted retroperitoneal débridement with postoperative lavage, was performed.

\section{Treatment}

Three ON strategies were used in the management of LIPN. Among them, continuous positive drainage via a large-bore double-lumen irrigation-suction tube is one of the key techniques. The significance of positive drainage system has been confirmed by several studies $[4,13$, 14]. The procedure of $\mathrm{ON}$ consist of a laparotomy through a bilateral subcostal incision, after blunt removal of pancreatic and peri-pancreatic necrosis, several large-bore double-lumen irrigation-suction tube inserted for postoperative CPD (Fig. 1).

Additionally, jejunostomy was performed for enteral feeding and the abdomen was closed. The first group patients without suspected imminent or overt ischemia/ perforation before or during operation were performed ON alone. The second group patients associated with suspected imminent or overt ischemia/perforation before or during operation underwent colonic segmental resection (CSR) with proximal ostomy, as well as ON. The third group patients, in addition to $\mathrm{ON}$, underwent

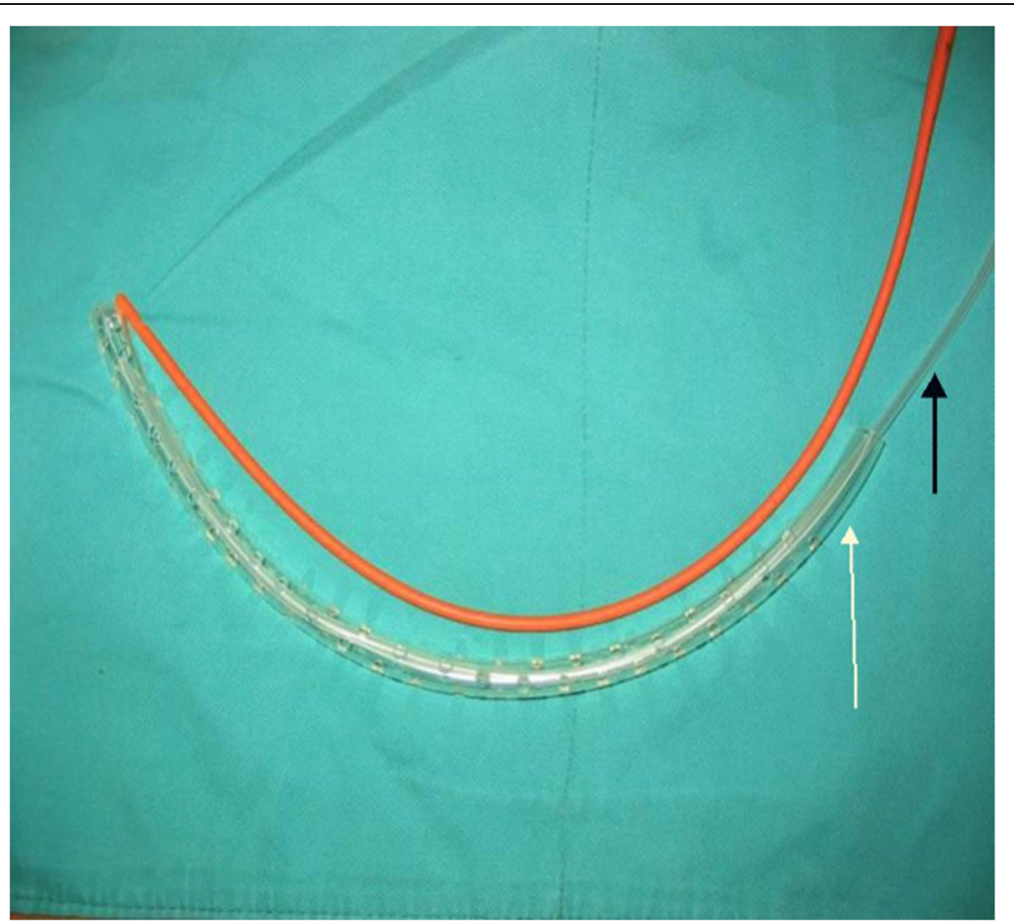

Fig. 1 Double-lumen irrigation-suction tube (DLIST) consists of a red irrigation catheter, a suction catheter (identified by black arrow), and a supporting pipe (identified by white arrow). It works under continuous negative pressure of 150 to 200 millibars along with continuous saline irrigation at $300 \mathrm{~mL} / \mathrm{h}$ 
PDLI, despite suspected imminent or overt ischemia/ perforation before or during operation. According to the different surgical procedures, they were divided into three groups, $\mathrm{ON}, \mathrm{ON}+\mathrm{CSR}$, and $\mathrm{ON}+\mathrm{PDLI}$.

\section{Statistical analysis}

SPSS software (SPSS for Windows, version 23.0, SPSS, Chicago, IL) was applied for statistical analysis. Measurement data was presented as median and interquartile range (IQR). Kruskal-Wallis was performed to compare variance among three groups and Bonferroni correction was used to compare two groups. For categorical variables, chi-squared test was performed to compare the constituent ratio among the three groups. Fisher's exact test was performed between two groups. $P<0.05$ was considered as statistically significant.

\section{Results}

\section{Patient characteristics}

From January 2012 to December 2017, a total of 234 patients with IPN were admitted to our hospital, of which 65 patients were performed with open surgery. Fortytwo patients were treated with ON for LIPN after failed minimally invasive approach were enrolled in the retrospective cohort study. The other 23 patients were excluded as the following reasons. Five patients underwent laparostomy for ACS, 5 patients underwent laparotomy for abdominal hemorrhage, 1 patient was traumarelated, 7 patients received exploratory laparostomy in other hospital and 5 patients with incomplete clinical data. (Fig. 2).

All the enrolled 42 patients were divided into three groups, 23 patients in ON group, 8 in $\mathrm{ON}+\mathrm{CSR}$ group and 11 in ON+PDLI group, according to the different surgical procedures. Patients in the three treatment groups had similar demographic and clinical characteristics. The major disease causes of these patients included biliary disease, alcohol and hyperlipidemia. There were no significant differences of age, gender, BMI, smoking history, and history of alcohol intake in patients among three groups. (Table 1).

\section{Comparison of inflammatory factors}

The inflammatory factors, including WBC, PCT, CRP and IL-6, in patients from all groups were lower than that before the treatment. As the course of treatment progressed, the level of the inflammatory factors decreased gradually. IL- 6 at the 3rd day in the ON+PDLI group was remarkable lower than the $\mathrm{ON}+\mathrm{CSR}$ group $(p<0.05)$. Meanwhile, at the 3rd day, PCT in the ON+PDLI group was also lower than the ON group $(p<0.05)$. At the 7th day, CRP in the ON+PDLI group was significantly lower than that in the $\mathrm{ON}$ group $(p=0.002)$. (Fig. 3).

\section{Comparison of treatment scores}

At the 3th day after surgery, the SOFA score in the $\mathrm{ON}+\mathrm{PDLI}$ group was significantly lower than the $\mathrm{ON}$ group and $\mathrm{ON}+\mathrm{CSR}$ group $(p<0.05)$. (Fig. $4 \mathrm{a}) \mathrm{APACHE}$

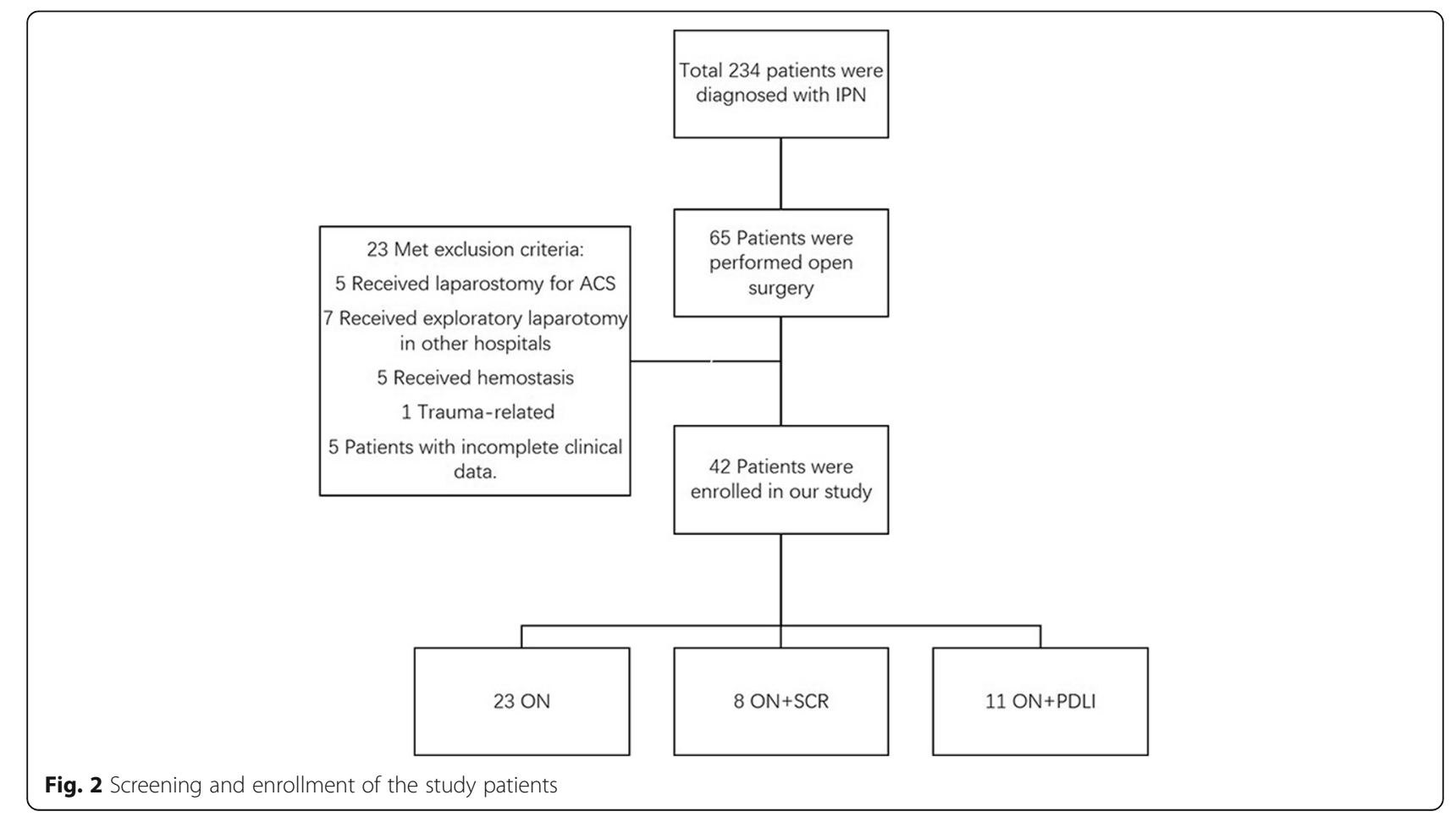


Table 1 Demographic characteristics

\begin{tabular}{|c|c|c|c|c|}
\hline Characteristic & $\begin{array}{l}\mathrm{ON} \\
N=23\end{array}$ & $\begin{array}{l}\mathrm{ON}+\mathrm{SCR} \\
\mathrm{N}=8\end{array}$ & $\begin{array}{l}\text { ON+PDLI } \\
N=11\end{array}$ & $p$ \\
\hline Age, median (IQR), year & $54(27-67)$ & $41.5(34.5-64.5)$ & $47(32-54)$ & 0.638 \\
\hline Gender, male/female & $15 / 8$ & $4 / 4$ & $5 / 6$ & 0.587 \\
\hline BMI, median (IQR) & $22.5(20.7-25.4)$ & $23.0(20.5-24.95)$ & $22.4(20.6-24.3)$ & 0.87 \\
\hline \multicolumn{5}{|l|}{ Pathogenesis (\%) } \\
\hline Biliary & 11 & 4 & 5 & 1.00 \\
\hline Alcohol & 6 & 2 & 3 & 1.00 \\
\hline Hypertriglyceridemia & 4 & 1 & 3 & 0.759 \\
\hline Other & 2 & 1 & 0 & 0.758 \\
\hline \multicolumn{5}{|l|}{ Nonmedical history } \\
\hline Smoking & 12 & 3 & 4 & 0.644 \\
\hline Drinking & 8 & 2 & 4 & 1.00 \\
\hline
\end{tabular}

Note: Kruskal-Wallis was performed to compare variance among three groups. For categorical variables, chi-squared test was performed to compare the constituent ratio among the three groups

II score showed a similar disease severity among patients within $24 \mathrm{~h}$ before open surgery in all groups $[16.50$ (IQR12-18) for ON group, 17.0 (IQR11-19) for $\mathrm{ON}+\mathrm{CSR}$ group and 16.0(IQR9-18) for ON+PDLI group, $p=1.00)]$. Our results showed systematic condition was improved in all groups after treatment. However, it was significant in the ON+PDLI group than in the $\mathrm{ON}+\mathrm{CSR}$ at the 3th day after surgery $(p<0.05)$. (Fig. 4b).

\section{Primary endpoints}

In ON group, 13 patients (56.5\%) had colonic complication, including 2 patients with colonic fistula, 4 patients with colonic stenosis, 2 patients with colonic fistula, 2
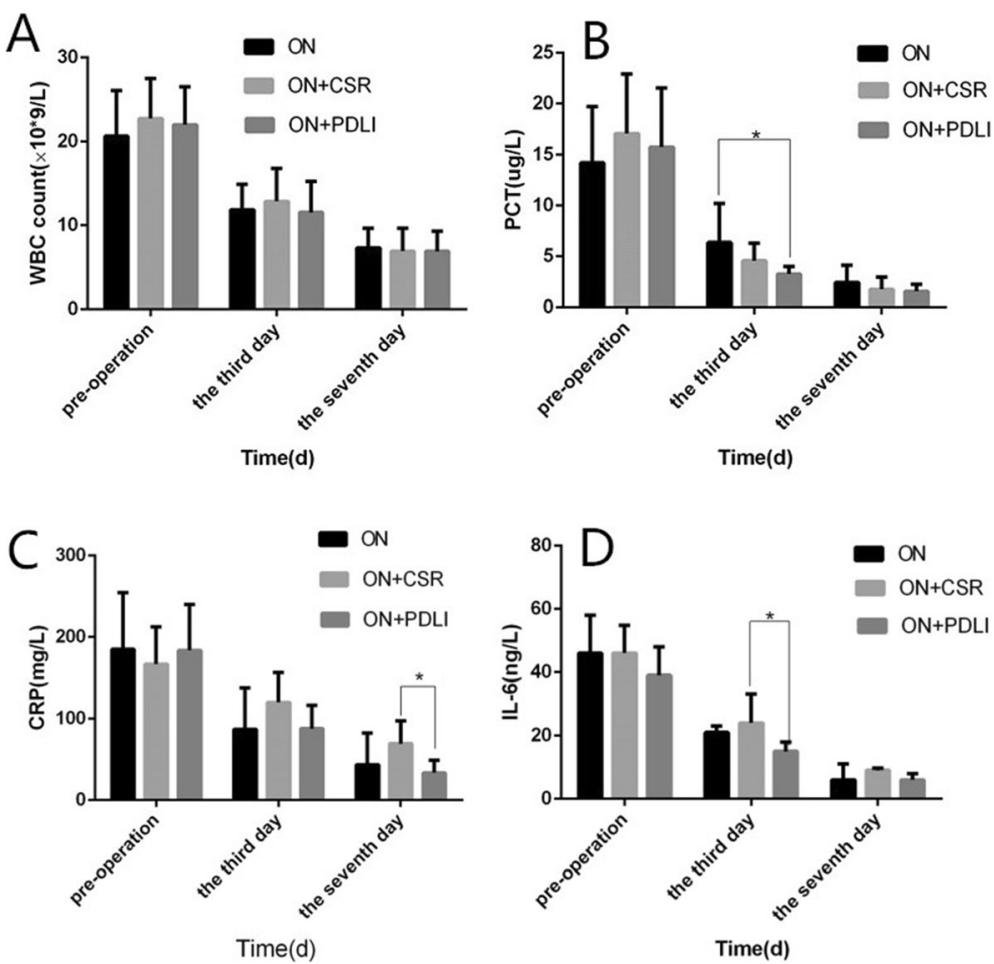

Fig. 3 Comparison of laboratory indicators. a. WBC was decreased in all groups, but there was no significant difference in the three groups; $\mathbf{b}$. The reduction of PCT in the ON+PDLI group was greater than that in the ON group at the 3rd day after operation; $\mathbf{c}$. The CRP improvement in the ON+PDLI group was better than that in the ON+CSR group at the 7th day after operation; $\mathbf{d}$. The reduction of IL-6 in the ON+PDLI group was better than the ON+CSR group at the 3rd day after operation 

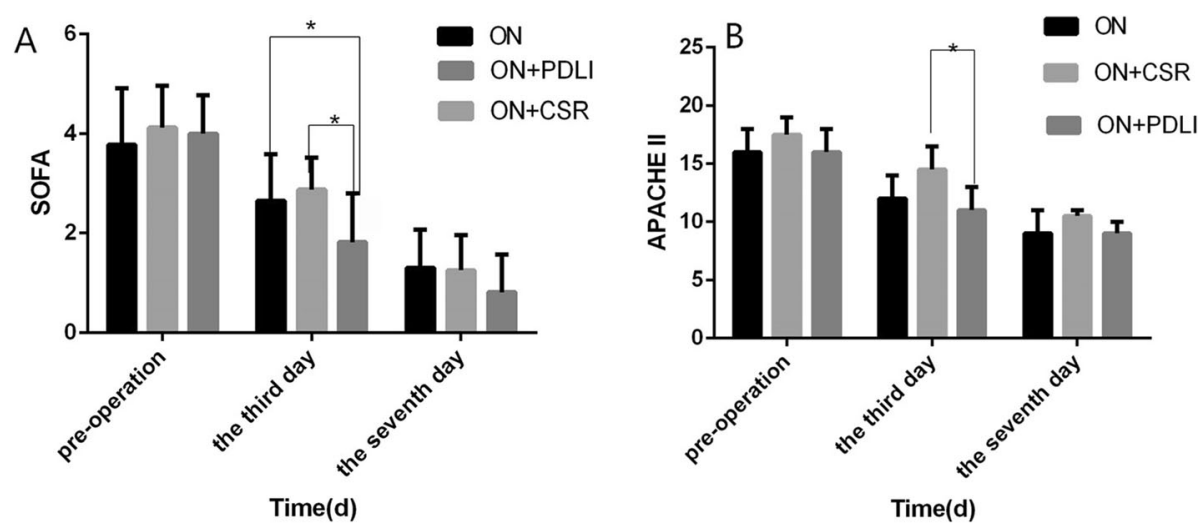

Fig. 4 Comparison of treatment scores. a. SOFA score of the ON+PDLI group was better than that of the ON group and ON+CSR group at the 3rd day after operation; $\mathbf{b}$. APACHE II score of the ON+PDLI group was better than that of the ON+CSR group at the 3rd day after operation

patients with stenosis, 3 patients with pseudoobstruction, 1 patients with duodenocolonic fistula and 1 patients with biliary-colon fistula. The complication rate decreased to $27.3 \%$ (3/11 patients) in ON+PDLI groups, consisting of colonic fistula in 1 case, colonic stenosis in 1 case and colonic fistula with stenosis in 1 case. The incidence rate of colonic complication in $\mathrm{ON}+\mathrm{PDLI}$ group was lower than that in the ON, but there was no significant difference $(p=0.11)$. In the $\mathrm{ON}$ group, 7 cases underwent re-operative ileostomy or colostomy due to colonic complication. Comparing to the $\mathrm{ON}+\mathrm{PDLI}$ group, the rate of re-surgery in ON group

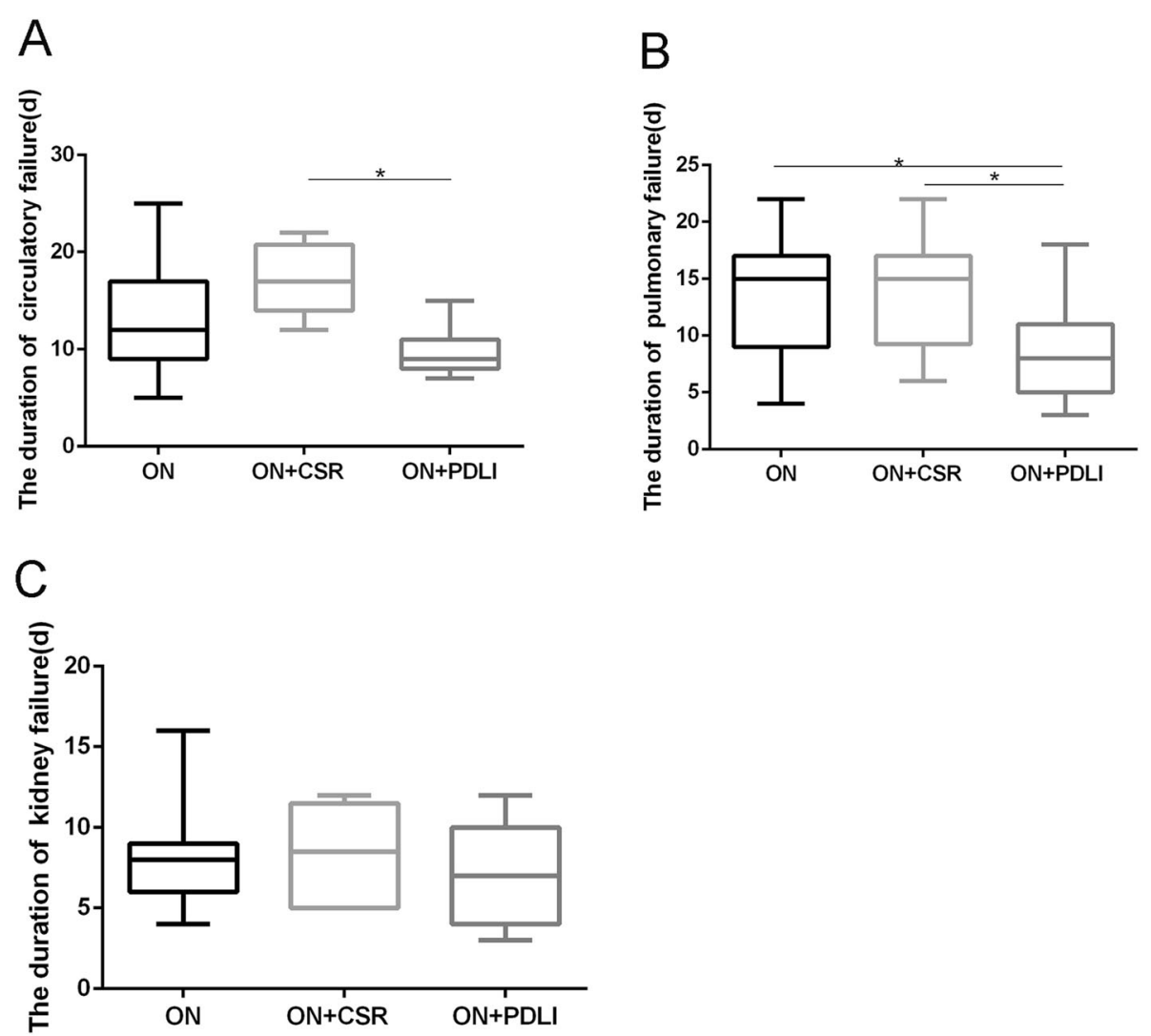

Fig. 5 Comparison of during of the organ failure. a The duration of circulatory failure of the ON+PDLI group was shorter than that of the $\mathrm{ON}+\mathrm{CSR}$ group; $\mathbf{b}$ The duration of pulmonary failure of the ON+PDLI group was shorter than that of the ON group and ON+CSR group after treatment 
was significantly higher $(P=0.04)$. As for the other major complications including pancreatic fistula, hemorrhage, and death showed no significant differences in the three groups. In addition, in the ON+CSR group, 5/8 patients were colonic necrosis/perforation, $3 / 8$ patients were pericolitis and fat necrosis, which were confirmed by histological examination.

The duration of postoperative circulatory failure was 12 (9-17), 17 (14-20) and 9 (8-11) days in ON, $\mathrm{ON}+\mathrm{CSR}$ and $\mathrm{ON}+\mathrm{PDLI}$ groups respectively. A remarkable decrease of postoperative duration of circulatory failure existed in ON+PDLI group compared with $\mathrm{ON}+\mathrm{CSR}$ group $(p=0.004)$. (Fig. 5a) Meanwhile, the duration of postoperative pulmonary failure in $\mathrm{ON}+\mathrm{P}$ DLI group was also significantly shorter than that in $\mathrm{ON}$ group and in $\mathrm{ON}+\mathrm{CSR}$ group $(p=0.012, p=0.026$, respectively). (Fig. 5b) There was no significant difference of duration of postoperative renal failure among the three groups $(p=0.438$, Fig. 5 c). (Table 2$)$.

\section{Secondary endpoints}

The median time from AP onset to open surgery was 25 (19-35), 44 (34-54), and 22 (15-34) days in ON, $\mathrm{ON}+\mathrm{CSR}$ and $\mathrm{ON}+\mathrm{PDLI}$ groups respectively. The median days in $\mathrm{ON}+\mathrm{CSR}$ group were significantly longer than that of in the ON $(p=0.0011)$ and ON+PDLI groups $(p=0.0069)$.
The median hospital stays in ON group [98 (87-102) days] were similar to that of the ON+CSR group [95.5 (72.5-129.8) days], while the days in ON+PDLI group were significantly shorter than the ON groups (Fig. 6a). Higher hospitalization cost was observed in the ON group than that in the ON+CSR and ON+PDLI group, however, there was only significantly difference between the ON group and ON+DPLI group $(p=0.0052)$ (Fig. $6 \mathrm{~b})$. Additionally, it was notable that patients treated by ON approach had longer time interval between operation to TEN than the $\mathrm{ON}+\mathrm{CSR}$ group and $\mathrm{ON}+\mathrm{PDLI}$ group ( $p=0.0085, \mathrm{p}<0.0001$ respectively) (Fig. 6c). (Table 3).

\section{Discussion}

Severe acute pancreatitis (SAP) is a serious disease involving multiple disciplines and systems. IPN is a complication of SAP at its end stage, with a high mortality rate $(14-69 \%)$ due to multiple organ failure, despite advances in critical care and surgical technique [21]. IPN is of great importance to surgeons, because medical management alone does not reduce mortality. With the development of minimally invasive treatment, step-up approaches combining new minimally invasive techniques seem to gradually replace the traditional $\mathrm{ON}$ and become the mainstream of IPN therapy, in which the major complications and mortality were lower compared with ON [6]. However, open surgery still plays an

Table 2 Primary endpoints

\begin{tabular}{|c|c|c|c|c|}
\hline & $\begin{array}{l}\mathrm{ON} \\
N=23\end{array}$ & $\begin{array}{l}\mathrm{ON}+\mathrm{SC} \\
\mathrm{N}=8\end{array}$ & $\begin{array}{l}\text { ON+PDLI } \\
N=11\end{array}$ & $\mathrm{p}$ \\
\hline The duration of postoperative circulatory failure, median (IQR), days & $12(9-17)$ & $17(14-20)$ & $9(8-11)$ & 0.0068 \\
\hline The duration of postoperative pulmonary failure, median (IQR), days & $15(8-19)$ & $16(9-25)$ & $8(5-11)$ & 0.026 \\
\hline The duration of postoperative kidney failure, median (IQR), days & $8(6-9)$ & $8(5-11.5)$ & $7(4-10)$ & 0.438 \\
\hline new-onset colonic complication no. (\%) & $13(56.5)$ & & $3(27.3)$ & 0.11 \\
\hline Colonic fistula & 2 & & 1 & \\
\hline Colonic stenosis & 4 & & 1 & \\
\hline Colonic fistula with stenosis & 2 & & 1 & \\
\hline pseudo-obstruction & 3 & & & \\
\hline duodenocolonic fistula, & 1 & & & \\
\hline biliary-colon fistula & 1 & & & \\
\hline sequence ileostomy or colostomy no. (\%) & $7(30.4)$ & & 0 & 0.04 \\
\hline Pancreatic fistula & 11 & 3 & 4 & 0.75 \\
\hline hemorrhage & 3 & 1 & 1 & 1.00 \\
\hline Intra-abdominal bleeding & 2 & 1 & 1 & \\
\hline Gastrointestinal bleeding & 1 & & & \\
\hline death no. (\%) & $3(13.0)$ & $2(25)$ & $1(9.1)$ & 1.00 \\
\hline $\begin{array}{l}\text { Colonic necrosis/perforation } \\
\text { confirmed by histological examination. }\end{array}$ & & 5 & & \\
\hline
\end{tabular}

Note: Kruskal-Wallis was performed to compare variance among three groups and Bonferroni correction was used to compare two groups. For categorical variables, chi-squared test was performed to compare the constituent ratio among the three groups. Fisher's exact test was performed between two groups 

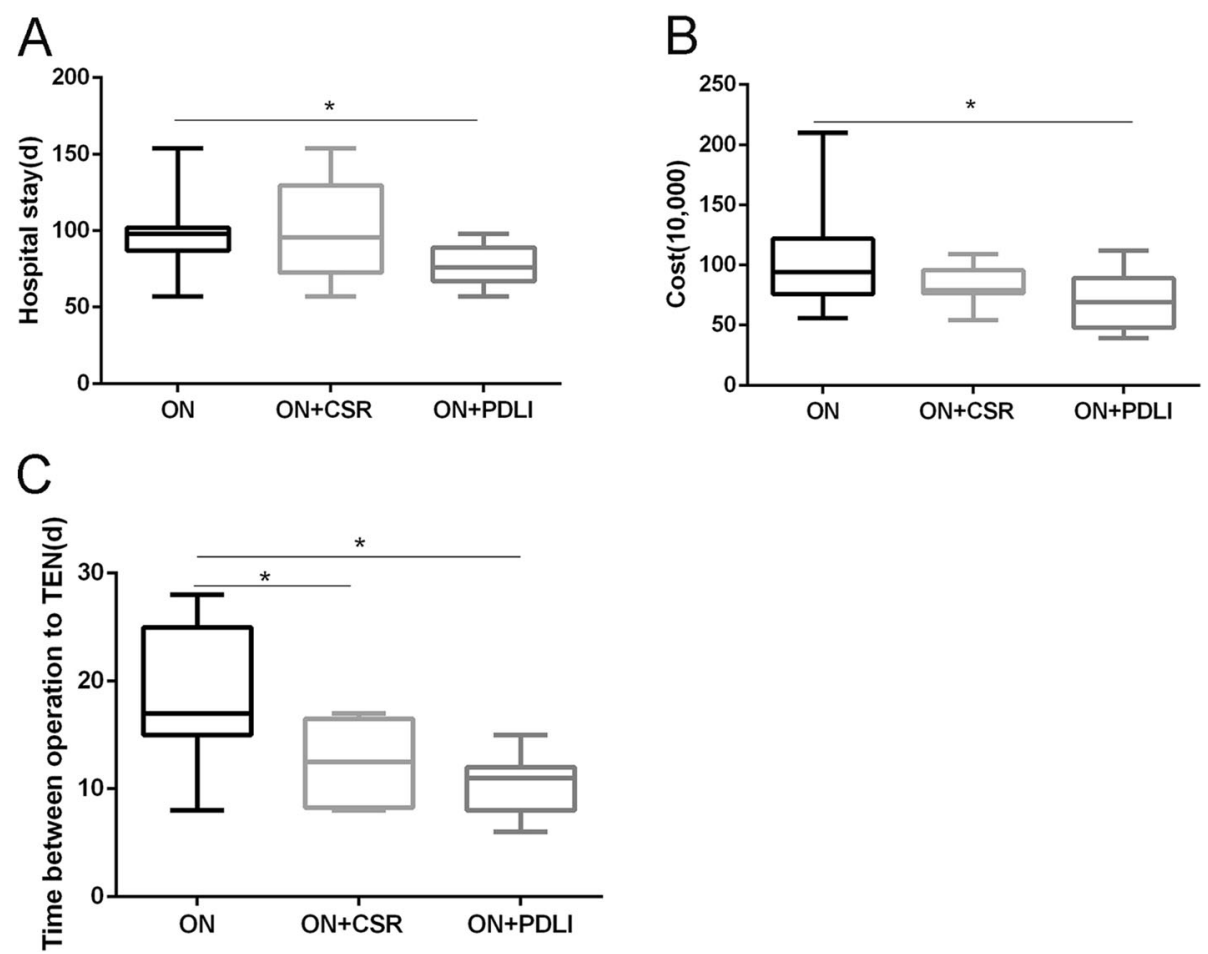

Fig. 6 Comparison of clinical indicators. a. The length of stay in the ON+PDLI group was shorter than the ON group; b. The hospitalization cost in the ON+PDLI group was less than the ON group; $\mathbf{c}$. The time interval between operation and TEN in the ON group was longer than the $\mathrm{ON}+\mathrm{CSR}$ group and ON+PDLI group

irreplaceable role in the treatment of SAP complications such as gastrointestinal fistula, hemorrhage, ACS, LIPN, $10-20 \%$ patients with IPN still underwent ON eventually [22]. The operations used for LIPN are aimed at removing dead or devitalized tissue, draining pus, providing a safer avenue for egress of pancreatic secretions and the leakage of gastrointestinal tract, and managing the colonic complications. For ON, inappropriate surgical procedures will aggravate the systemic pathophysiologic disturbances, sepsis shock, and MOF, which may cause catastrophic consequences or even death. The optimal $\mathrm{ON}$ techniques are of great significance in decreasing major post-operative complications, shortening hospital stay, and reducing the morbidity and mortality of patients [23]. Lavage system with large-bore drains constitute the most recommended option based on the reducing mortality, which is supported by the results of several randomized controlled trials [24, 25]. Our study confirmed that continuous positive drainage via a largebore double-lumen irrigation-suction tube is the pivotal techniques in ensuring adequate drainage. None of the patients underwent reoperation because of local sepsis. More controversies came from the management of colon complications.

Several researches recommend a low threshold for colonic resection due to suspected imminent or overt ischemia/perforation by outside inspection during surgery. But $12.5-50 \%$ patients who were performed with

Table 3 Secondary endpoints

\begin{tabular}{|c|c|c|c|c|}
\hline & $\begin{array}{l}\mathrm{ON} \\
N=23\end{array}$ & $\begin{array}{l}\mathrm{ON}+\mathrm{SC} \\
\mathrm{N}=8\end{array}$ & ON+PDLI N=11 & $P$ \\
\hline Time interval between AP onset to operation, median (IQR), days & $25(19-35)$ & $44(34-54)$ & $22(15-34)$ & 0.0052 \\
\hline Days in hospital, median (IQR), days & $98(87-102)$ & $95.5(72.5-129.8)$ & $76(67-89)$ & 0.0089 \\
\hline Cost, 10,000 median (IQR), CHY & $94(76-122)$ & $79(76-95)$ & $69(48-89)$ & 0.0188 \\
\hline Time interval between operation to TEN, median (IQR), days & $17(15-25)$ & $12.5(8.5-16.5)$ & $11(8-12)$ & 0.001 \\
\hline
\end{tabular}

Note: Kruskal-Wallis was performed to compare variance among three groups 
aggressive surgical approach suffered innocent colonic resection without ischemia/perforation $[12,15,16]$. Just evaluating the outer aspect of the colon, identification of colon involvement may be difficult because of nonspecific symptoms or being masked by the sepsis. Borie D et al. [11] demonstrated that diverting loop ileostomy should also be performed in IPN when colonic viability was dubious. Up to now, comparing the role of DLI and the aggressive form of treatment such as subtotal/segment colectomy in terms of clinic outcome and prognosis, there is no data to suggest that which one is more advantageous in treating IPN patients with the suspected imminent or overt ischemia/perforation before or during operation. Additionally, many postoperative patients without suspected imminent or overt ischemia/perforation before or during surgery have got colonic complications such as stenosis, pseudo-obstruction, and even new-onset ischemia/perforation.

Sustained colonic complications may prolong parenteral nutritional support, which is attended by potential poor prognosis [26]. Many researches reported colonic fistulas occuring in 15-53\% patients after necrosectomy and drainage [27-29]. In addition to pancreatic fistula, colonic fistulas were the second frequently postoperative complication of ON [30,31]. Mohamed SR et al. advocate surgery for colonic fistulae, which have the worst outcome, possibly due to local sepsis [32]. Jiang et al. reported sequence ileostomy or colostomy was performed for $61.1 \%$ (44/72) colonic fistula [15]. As showed in our ON group, $17.4 \%(4 / 23)$ cases suffered post-operation colonic fistulae. Re-operation ileostomy or colostomy was performed $53.8 \%(7 / 13)$ for colonic complications. Untimely diagnosis of colon complications is a main cause of prolonged hospital stay, which increased costs and high mortality [33].

In the current study, WBC, CPR, PCT and IL-6 were chosen as indicators of the infection and inflammatory response [34-36]. The results showed that patients treated with ON+PDLI experienced a more rapid improvement in inflammation over time, especially on the third day after operation. Therefore, we consider that $\mathrm{ON}+\mathrm{PDLI}$ can improve systemic infection, and reduce the inflammatory response promptly. According to the APACHE II score and the SOFA score, there was no significant difference of the severity of disease among patients in the three groups within $24 \mathrm{~h}$ before operation. Compared with ON, ON+PDLI did not increase the damage of patients. Consistent with inflammatory factors, the recovery time of organ function in ON+PDLI group was shorter than that in other two groups. The ON+PDLI was more aligned with the damage control principal [37]. The operation time, complexity and traumatic stress response in $\mathrm{ON}+\mathrm{CSR}$ group were significantly higher than in ON+PDLI group, which would inevitably lead to longer recovery time of organ function. Another study reported that postoperative mortality was as high as $50 \%$ with the aggressive surgical approach [17]. During the ON for LIPN, the colon was edematous grossly and adhered to the surrounding tissue. It is inevitable that the surrounding organs may be damaged during the operation, especially in the hepatic flexure and splenic flexure. In our ON+CSR group, the splenic flexure could not be dissociated from spleen easily in one patient. After separation, hemorrhage occurring in splenic hilum, the spleen and part of the colon were resected together, which increased the operation time and aggravated the surgical trauma. Although the operation was completed, the patient finally died of multiple organ failure after operation. However, in ON+PDLI group, two patients with confirmed colonic necrosis or perforation during operation were performed with $\mathrm{CPD}$ via DLIST and PDLI, which not only conformed to the damage control concept, but also made full use of intestinal function after operation. In ON group, 13/23 patients with colonic complication could not made full use of intestinal function after operation for colon in circulation. It revealed that $\mathrm{ON}$ patients profited more from the CPD via DLIST and PDLI in terms of duration of organ failure, local and systemic complications. Besides, length of hospital stay was compared in the three groups, despite the additional intraoperative procedures, the ON+PDLI did not prolong and even tended to reduce the length of hospital stay. When ON+PDLI approach administrated, the costs in hospital was markedly reduced, and the time interval from operation to total enteral nutrition was significantly shorten, which implied substantial economic and resource-saving benefits, although there was no significant difference in the mortality.

Patients with LIPN who underwent ON could benefit from CPD + PDLI approach as follows. Continuous positive drainage via a large-bore double-lumen irrigationsuction tube is one of the key techniques to ensure adequate drainage after operation. Early enteral nutrition can be started with PLDI. According to the clinical manifestations, we can adjust the strategy of enteral nutrition timely and safely, which can implement total enteral nutrition as early as possible by keeping colon out of circuit. This is important to protect the gut barrier, reduce bacterial translocation, and even decrease the morbidity and mortality by reducing the septic complications. PDLI can manage the diversion proctocolitis by antegrade succus entericus reinfusion, which may also prevent the colonic complications such as diarrhea, obstruction, missing colon fistula and stenosis after performing closure of the stoma [38, 39]. PDLI could decrease the rate of reoperation, the hospitalization time and cost of hospitalization. It avoids the resection of 
innocent colon and is more in line with the damage control concept.

There were also some limitations in this study. First, it was a retrospective cohort study with a small sample size. Large samples randomized controlled study should be needed for in-depth investigation in the future. Second, intraoperative bleeding patients were excluded, and the effect of PDLI in these patients has not been evaluated. Furthermore, complications such as post-operative bleeding cannot be avoided, and there is no significant reduction in post-operative mortality. Finally, the time to pulmonary, circulatory and kidney failure were not evaluated in this study. Therefore, whether patients would have developed these outcomes after discharge was still unknown. Further study was needed to evaluate these outcomes.

\section{Conclusion}

Our study suggests that CPD has initially solved the problem of inadequate drainage after $\mathrm{ON}$. Though it may be impossible to control for all the operative and surgical variation that inherently exists in the management of LIPN, our study may provide a new strategy for treatment of LIPN.

\begin{abstract}
Abbreviations
LIPN: Late infected pancreatic necrosis; ON: Open necrosectomy; ON+CSR: Open necrosectomy with colonic segment resection; ON+PDLI: Open necrosectomy with prophylactic diverting loop ileostomy; TEN: Total enteral nutrition; CPD: Continuous positive drainage; SAP: Severe acute pancreatitis; DLIST: Double-lumen irrigation-suction tube; DLI: Diverting loop ileostomy; ACS: Abdominal compartment syndrome; BMI: Body mass index; APACHE: Acute physiology and chronic health evaluation; SOFA: Sequential organ failure assessment; CRP: C-reactive protein; PCT: Procalcitonin; WBC: White blood cells; TEN: Total enteral nutrition; CSR: Colonic segmental resection; IQR: Interquartile range
\end{abstract}

\section{Acknowledgements}

None.

\begin{abstract}
Authors' contributions
guarantor of integrity of the entire stud: DG N. study concepts: $Y Z Z$. study design: DG N, YZ Z. definition of intellectual content: $Y Z Z$. literature research: DG N. clinical studies: WQ L, C L. experimental studies: WQ L. data acquisition: Q H, LA D. data analysis: Q H. statistical analysis: WL T. manuscript preparation: F Y, HC F. manuscript editing: F Y. manuscript review: YZ Z. All authors have read and approved the manuscript.
\end{abstract}

\section{Funding}

None.

\section{Availability of data and materials}

The datasets used or analysed during the current study are available from the corresponding author on reasonable request.

\section{Ethics approval and consent to participate}

The study was approved by the Institutional Review Board of Jinling hospital. Written informed consent was obtained.

\section{Consent for publication}

Not Applicable.

\section{Competing interests}

None.

\section{Author details}

${ }^{1}$ Department of General Surgery, Jinling clinical college of Nanjing Medical University, Nanjing 210002, Jiangsu, China. ${ }^{2}$ Gastrointestinal Surgery Department, Affiliated Hospital of Qingdao University, Qingdao 266000, Shandong, China. ${ }^{3}$ Oncology Department, Xintai people's Hospital, Tai'an 271200, Shandong, China. ${ }^{4}$ Department of General Surgery, Jinling clinical college of Nanjing Medical University, 305 East Zhongshan Road, Nanjing 210000, Jiangsu, China.

Received: 20 January 2019 Accepted: 9 June 2020

Published online: 08 July 2020

\section{References}

1. Uhl W, Warshaw A, Imrie C, Bassi C, McKay CJ, Lankisch PG, Carter R, Di Magno E, Banks PA, Whitcomb DC, Dervenis C, Ulrich CD, Satake K, Ghaneh P, Hartwig W, Werner J, McEntee G, Neoptolemos JP, Büchler MW. International association of pancreatology IAP guidelines for the surgical management of acute pancreatitis. Pancreatology. 2002;2:565-73.

2. Besselink MG, van Santvoort HC, Buskens E, Boermeester MA, van Goor H, Timmerman HM, Nieuwenhuijs VB, Bollen TL, van Ramshorst B, Witteman BJ, Rosman C, Ploeg RJ, Brink MA, Schaapherder AF, Dejong CH, Wahab PJ, van Laarhoven CJ, van der Harst E, van Eijck CH, Cuesta MA, Akkermans LM, Gooszen HG. Acute Pancreatitis Werkgroep Nederland. Probiotic prophylaxis in predicted severe acute pancreatitis: a randomised, double-blind, placebocontrolled trial. Lancet. 2008;371:651-9.

3. Rodriguez JR, Razo AO, Targarona J, Thayer SP, Rattner DW, Warshaw AL, Fernández-del CC. Debridement and closed packing for sterile or infected necrotizing pancreatitis: insights into indications and outcomes in 167 patients. Ann Surg. 2008;247:294-9.

4. Raraty MG, Halloran CM, Dodd S, Ghaneh P, Connor S, Evans J, Sutton R, Neoptolemos JP. Minimal access retroperitoneal pancreatic necrosectomy: improvement in morbidity and mortality with a less invasive approach. Ann Surg. 2010;251:787-93.

5. Petrov MS, Shanbhag S, Chakraborty M, Phillips AR, Windsor JA. Organ failure and infection of pancreatic necrosis as determinants of mortality in patients with acute pancreatitis. Gastroenterology. 2010;139:813-20.

6. van Santvoort HC, Besselink MG, Bakker OJ, Hofker HS, Boermeester MA, Dejong $\mathrm{CH}$, van Goor $\mathrm{H}$, Schaapherder AF, van Eijck $\mathrm{CH}$, Bollen $\mathrm{TL}$, van Ramshorst B, Nieuwenhuijs VB, Timmer R, Laméris JS, Kruyt PM, Manusama ER, van der Harst E, van der Schelling GP, Karsten T, Hesselink EJ, van Laarhoven CJ, Rosman C, Bosscha K, de Wit RJ, Houdijk AP, van Leeuwen MS, Buskens E, Gooszen HG, Dutch Pancreatitis Study Group. A step-up approach or open necrosectomy for necrotizing pancreatitis. N Engl J Med. 2010;362(16):1491-502.

7. van Santvoort HC, Bakker OJ, Bollen TL, Besselink MG, Ahmed Ali U, Schrijver AM, Boermeester MA, van Goor H, Dejong CH, van Eijck CH, van Ramshorst B, Schaapherder AF, van der Harst E, Hofker S, Nieuwenhuijs VB, Brink MA, Kruyt PM, Manusama ER, van der Schelling GP, Karsten T, Hesselink EJ, van Laarhoven CJ, Rosman C, Bosscha K, de Wit RJ, Houdijk AP, Cuesta MA, Wahab PJ, Gooszen HG, Dutch Pancreatitis Study Group. A conservative and minimally invasive approach to necrotizing pancreatitis improves outcome. Gastroenterology. 2011;141:1254-63.

8. Vasiliadis K, Papavasiliou C, Al Nimer A, Lamprou N, Makridis C. The role of open necrosectomy in the current management of acute necrotizing pancreatitis: a review article. ISRN Surg. 2013;2013:579435.

9. Bradley EL III. A fifteen year experience with open drainage for infected pancreatic necrosis. Surg Gynecol Obstet. 1993;177(3):215-22.

10. Rau B, Bothe A, Beger HG. Surgical treatment of necrotizing pancreatitis by necrosectomy and closed lavage: changing patient characteristics and outcome in a 19-year, single-center series. Surgery. 2005;138(1):28-39.

11. Borie D, Frileux $P$, Tiret $E$, Berger A, Wind P, Levy E, Nordlinger B, Cugnenc $\mathrm{PH}$, Parc R. Diverting loop ileostomy, effective prevention of colonic complications in necrotizing acute pancreatitis. Ann Chir. 1992;46(1):51-8.

12. Nagpal AP, Soni H, Haribhakti S. Severe colonic complications requiring subtotal colectomy in acute necrotizing pancreatitis-a retrospective study of 8 patients. Indian J Surg. 2015;77(1):3-6.

13. Liu P, Song J, Ke HJ, Lv NH, Zhu Y, Zeng H, Zhu Y, Xia L, He WH, Li J, Huang $X$, Lei YP. Double-catheter lavage combined with percutaneous flexible endoscopic debridement for infected pancreatic necrosis failed to percutaneous catheter drainage. BMC Gastroenterol. 2017;17(1):155. 
14. Tong Z, Shen X, Ke L, Li G, Zhou J, Pan Y, Li B, Yang D, Li W, Li J. The effect of a novel minimally invasive strategy for infected necrotizing pancreatitis. Surg Endosc. 2017;31(11):4603-16.

15. Aldridge MC, Francis ND, Glazer G, Dudley HA. Colonic complications of severe acute pancreatitis. Br J Surg. 1989;76:362-7.

16. Borie D, Frileux P, Tiret E, Hannoun L, Simon R, Ollivier JM, Cugnenc PH, Levy E, Parc R. Colonic complications of acute necrotizing pancreatitis. Presse Méd. 1992;21:519-23.

17. Van Minnen LP, Besselink MG, Bosscha K, Van Leeuwen MS, Schipper ME, Gooszen HG. Colonic involvement in acute pancreatitis. A retrospective study of 16 patients. Dig Surg. 2004;21 (1):33-8 discussion 39-40. Epub 2003 Dec 29.

18. Dellinger EP, Forsmark CE, Layer P, Levy P, Maravi-Poma E, Petrov MS, Shimosegawa $T$, Siriwardena AK, Uomo G, Whitcomb DC, Windsor JA, Pancreatitis across nations clinical R, Education A. Determinant-based classification of acute pancreatitis severity: an international multidisciplinary consultation. Ann Surg. 2012;256:875-80.

19. Banks PA, Freeman ML. Practice guidelines in acute pancreatitis. Am J Gastroenterol. 2006;101:2379-400.

20. Banks PA, Bollen TL, Dervenis C, Gooszen HG, Johnson CD, Sarr MG, Tsiotos GG, Vege SS, Acute Pancreatitis Classification Working G. Classification of acute pancreatitis-2012: revision of the Atlanta classification and definitions by international consensus. Gut. 2013;62:102-11.

21. Tenner S, Baillie J, Dewitt J, Vege SS. American college of gastroenterology guidelines: management of acute pancreatitis. Am J Gastroenterol. 2013;108: 1400-15 1416

22. Werner J, Feuerbach S, Uhl W, Büchler MW. Management of acute pancreatitis: from surgery to interventional intensive care. Gut. 2005;54(3): $426-36$

23. Vasiliadis K, Papavasiliou C, Al Nimer A, Lamprou N, Makridis C. The Role of open necrosectomy in the current management of acute necrotizing pancreatitis: a review article. ISRN Surg. 2013;2013:579435.

24. Schneider L, Buchler MW, Werner J. Acute pancreatitis with an emphasis on infection. Infect Dis Clin N Am. 2010;24:921-41.

25. Nieuwenhuiis VB, Besselink MGH, vanMinnen LP, Gooszen HG. Surgical management of acute necrotizing pancreatitis: a 13-year experience and a systematic review. Scand J Gastroenterol. 2003;38(239):111-6.

26. Petrov MS, Pylypchuk RD, Uchugina AF. A systematic review on the timing of artificial nutrition in acute pancreatitis. Br J Nutr. 2009:101(6):787.

27. Bouillot $\mathrm{JL}$, Alexandre $J \mathrm{H}$, Vuong NP. Colonic involvement in acute necrotizing pancreatitis: results of surgical treatment. World J Surg. 1989:13:84-7.

28. Fernandez-del Castillo C, Rattner DW, Makary MA, Mostafavi A, McGrath D, Warshaw AL. Debridement and closed packing for the treatment of necrotizing pancreatitis. Ann Surg. 1998;228:676-84.

29. Jiang W, Tong Z, Yang D, Ke L, Shen X, Zhou J, Li G, Li W, Li J. Gastrointestinal fistulas in Acute Pancreatitis with infected pancreatic or Peripancreatic necrosis: a 4 year single-center experience. Medicine (Baltimore). 2016 Apr;95(14):e3318.

30. Tsiotos GG, Smith CD, Sarr MG. Incidence and management of pancreatic and enteric fistulas after surgical management of severe necrotizing pancreatitis. Arch Surg. 1995:130:48-52.

31. Martin RF, Hein AR. Operative Management of Acute Pancreatitis. Surg Clin North Am. 2013;93(3):595-610.

32. Mohamed SR, Siriwardena AK. Understanding the colonic complications of pancreatitis. Pancreatology. 2008;8:153-8.

33. Samy RM, Ajith KS. Understanding the colonic complications of pancreatitis. Pancreatology. 2008;8(2):153-8.

34. Al-Bahrani AZ, Ammori BJ. Clinical laboratory assessment of acute pancreatitis. Clin Chim Acta. 2005;362:26-48.

35. Munsell MA, Buscaglia JM. Acute pancreatitis. J Hosp Med. 2010;5:241-50.

36. Frossard JL, Steer ML, Pastor CM. Acute pancreatitis. Lancet. 2008;371:143-52.

37. Pommerening MJ, Kao LS, Sowards KJ, Wade CE, Holcomb JB, Cotton BA. Primary skin closure after damage control laparotomy. Br J Surg. 2015;102: 67-75.

38. Kabir SI, Kabir SA, Richards R, Ahmed J, MacFie J. Pathophysiology, clinical presentation and management of diversion colitis:a review of current literature. Int J Surg. 2014;12(10):1088-92.

39. Pal K, Tinalal S, Al Buainain H, Singh VP. Diversion proctocolitis and response to treatment with short-chain fatty acids--a clinicopathological study in children. Indian J Gastroenterol. 2015;34(4):292-9.

\section{Publisher's Note}

Springer Nature remains neutral with regard to jurisdictional claims in published maps and institutional affiliations.

Ready to submit your research? Choose BMC and benefit from:

- fast, convenient online submission

- thorough peer review by experienced researchers in your field

- rapid publication on acceptance

- support for research data, including large and complex data types

- gold Open Access which fosters wider collaboration and increased citations

- maximum visibility for your research: over $100 \mathrm{M}$ website views per year

At BMC, research is always in progress.

Learn more biomedcentral.com/submissions 